\title{
From Efficiency to Sufficiency: Insights from the Swiss Energy Transition
}

\author{
Laure Dobigny and Marlyne Sabakian
}

Abstract In the wake of the Fukushima nuclear disaster, the Swiss 2050 Energy Strategy aims to promote energy efficiency, renewable energy (RE) sources, and nuclear power phase-out. Against that backdrop, this chapter provides a brief overview of the socio-material dynamics of household energy use in Switzerland, highlighting the role of regional energy providers, and the influence of building standards and social norms on everyday energy usage. We then examine current energy policies, before turning to the characteristics of Swiss sustainable energy initiatives-highlighting the important role of research-and focus on a best practice effort to support sufficiency-based transformations. We conclude with some reflections on the importance of focusing on sufficiency, rather than efficiency, in the framing and design of energy initiatives aimed at households.

Keywords Building standards - Energy transition - Energy policy • Action-research · Switzerland

L. Dobigny $(\triangle) \cdot$ M. Sahakian

University of Geneva, Geneva, Switzerland

M. Sahakian

e-mail: Marlyne.Sahakian@unige.ch

(C) The Author(s) 2019

F. Fahy et al. (eds.), Energy Demand Challenges in Europe, https://doi.org/10.1007/978-3-030-20339-9_10 


\section{INTRODUCTION}

The Swiss energy system is relatively decentralized compared to neighbouring countries, with regional energy providers for electricity, gas, and district heating that generally take the form of private entities with the State as a primary stakeholder. Some private companies exist, as well as energy production cooperatives (citizen-led and producing renewables), but they are marginal compared to the role of public local companies in contributing to Swiss energy production and distribution. However, new consortiums between citizens and local public companies are emerging, particularly towards renewable energy (RE) generation and involving the implementation of RE plants with the financial participation of citizens. Through a citizen referendum in May 2017, Switzerland adopted the "2050 Energy Strategy" involving the following measures: lowering energy consumption, improving energy efficiency, and promoting RE. A progressive nuclear phase-out is also planned. Following a brief overview of socio-material dynamics of household energy use and energy policy in Switzerland, this chapter examines the characteristics of Swiss sustainable energy initiatives, and provides a good practice example of an initiative that seeks to contribute to sustainable transformation in the energy system through support for sufficiency-based lifestyles.

\section{Socio-Material Dynamics of Household Energy UsE IN SWITZERLAND}

A specificity in Switzerland is the system of central heating in buildings with estimated individualized heating bills for apartment units, and little to no thermostats. With the exception of metering in private homes, and the limited smart meters being deployed among households, there is little opportunity to apprehend detailed individual consumption for heating in apartments, as these are often calculated on an annual basis and bundled in with other utilities. Legislation in favour of individual bills for heating and hot water has been in place since 1993 for new building constructions. Further revisions of this legislation (the most recent one dated 2018) have included older building stock, albeit selectively. In buildings that boast the Swiss energy-efficiency label, Minergie, energy consumption is calculated by individual meters per apartment unit, and sophisticated floor heating systems result in the necessity to fine-tune hydraulic valves in order to adapt indoor temperatures. 
The "performance gap" (Gram-Hanssen and Georg 2017) between these highly-energy-efficient buildings and usage is relatively well recognized by engineering companies and developers in Switzerland. Currently, heating is mainly provided by fossil fuels (primarily petroleum and gas) and electricity is mainly produced by hydroelectricity $(60 \%)$ involving nuclear energy (32\%) (SFOE 2018).

Beyond the material arrangements of energy systems and building standards, there are also less visible ways to shape energy demand: social norms and related prescriptions also have an influence on how energyusing practices play out. In Switzerland, social norms around cleanliness and tidiness appear to be quite strong, as the Swiss adage "propre en ordre" (clean and in order) expresses, which have implications for energy-related practices, including laundry and cleaning. Other normative ways of doing may have more positive implications for energy usage: it is not unusual for apartment buildings to have a shared laundry facility, for washing and drying clothes (e.g. in a heated room in the basement), although private ownership is on the rise. Laundry machine purchases have grown exponentially in the past decades, along with the normalization of dryers (Sahakian and Bertho 2018). Nevertheless, the new trend towards social and ecological building cooperatives means that collective laundry rooms are still being designed into these buildings, albeit on a small scale. In the mobility domain, while private cars are the preferred means of transport for many, public transport is quite efficient and car/bike sharing is becoming more popular. There are also public events to "slow down", involving biking and walking in city centres. In September 2018, and with the Votation Vélo (Bike Vote), 73.4\% of Swiss voters agreed to integrate the right to bike lanes into the Constitution, on equal footing with pedestrian ways; yet how this will translate into local implementation remains to be seen.

\section{Energy Policy in Switzerland}

Partly due to a reaction to the Fukushima nuclear disaster, Switzerland has adopted a "2050 Energy Strategy" (Swiss Confederation 2016). In addition to reduced energy usage, mostly expected through efficient appliances and buildings, and the promotion of RE sources, new nuclear power plant construction is prohibited and a progressive nuclear phaseout is planned. To set up these objectives, the government is promoting refurbishment of buildings (by providing monetary incentives for 
owners to switch from oil heating systems to heat pumps, or towards insulation works); energy efficiency for appliances (through monetary incentives) as well as for cars (by enacting binding legislation); RE implementation (via the introduction of monetary schemes similar to feed-in tariffs in other European countries); the promotion of RE production and usage among households and at the neighbourhood level; and smart metering in households. Smart technologies are in a pilot phase, but a recent report by the Swiss government signals that such technologies are on the rise-put forward with the hope of engendering greater energy efficiencies in relation to systems of distribution. The Swiss government is also supporting research in energy transitions, focused mainly on technical innovations, but with more modest financial support dedicated to socio-economic aspects of energy production and consumption.

Due to the Swiss energy system, made up of mostly local and public utilities, and a participative democracy where citizens engage with energy issues (through regional and national referendums), there is a degree of trust in the local utilities by the general population, and towards the energy transition.

\section{Trends in Energy Initiatives Aimed at Swiss Households}

In Swiss campaigns, and when it comes to tackling the demand side of energy usage, individual actions and efficiency measures are mainly being promoted: for example, turning off lights and appliances, changing old energy-intensive appliances for more efficient models (e.g. fridge), or other technical changes in the household (e.g. buying LED bulbs, by offering a special discount), among others. Local utilities, federal institutions, environmental NGOs and associations mostly lead these campaigns. There are also some efforts to promote solidarity between the so-called Global North and Global South: for example, initiatives to save energy in Switzerland, with savings invested in RE schemes elsewhere.

A key characteristic in Switzerland is the number of Sustainable Energy Consumption Initiatives (SECIs) that are led by academics and research teams. This is due to an ambitious national research 
Table 10.1 Number of national SECIs in Switzerland according to their problem framing

policy that supported research programmes on energy issues in the past decade, as mentioned above. As a result, numerous initiatives aimed at improving household energy usage (and systems more generally) are underway in Switzerland, engaging with innovative processes such living labs and action research, with new collaborations underway between municipal actors, energy companies and researchers (Sahakian and Dobigny 2019). A review of SECIs in Switzerland according to their problem framing reflects this trend: SECIs that promote changes in complex interactions and in everyday life situations (Table 10.1) are more numerous than in other European countries (Jensen et al. 2018).

Swiss SECIs also reflect the specificities of energy consumption in Switzerland, such as the significance of individual car usage. Several SECIs therefore propose initiatives aimed at changing mobility options, by promoting biking and e-biking, bike and car sharing, or public transport usage (for example, Bike4car and Publi Bike). Encouraging sufficiency measures or challenging the social norms tied up with un-sustainable energy usage are less common in the Swiss SECIs. Pumpipumpe offers a counter example, as detailed in the case study below. 


\section{Case Study: Pumpipumpe ${ }^{1}$}

The case study selected for Switzerland demonstrates how initiatives can focus on changes in everyday life situations, towards an overall aim of reducing (energy) consumption, but not based solely on information campaigns around energy or the introduction of more efficient appliances. Launched in Switzerland in 2012, Pumpipumpe is a platform to promote the sharing of appliances and other household items between neighbours. According to Sahakian (2017), the two founders were sharing a workspace in 2012 when they came up with the idea of creating a way for people to share everyday household items. In developing a sharing platform, the duo decided to work at the level of neighbourhoods, where they saw enormous potential. They came up with the idea of using the mailbox as a personal space and communication tool: the Pumpipumpe sticker system allows people to place specially designed labels directly on their mailbox, illustrating different household items (e.g. drill, ladder, books, and toys) that they are willing to share.

\section{Methods for Intervention}

The aim of the project Pumpipumpe is to reduce the purchase of household items while promoting the sharing of consumer goods and community relations. A secondary objective is to prompt a change in how products are designed, with longevity-by-design in mind. The social dimensions of this initiative are put forward: sharing takes place through local networks, improving social interaction in urban neighbourhoods in geographic communities of place rather than solely online. An online platform was also launched allowing participants to order stickers, and more recently, in 2015, access an online interactive map, where people can see what items are available for sharing in their neighbourhood. Stickers can also be ordered in partner shops, from Pumpipumpe ambassadors, or from individuals who purchase several sheets of stickers to share with their contacts.

\footnotetext{
${ }^{1}$ http://www.pumpipumpe.ch.
} 


\section{Framing the Energy Challenge}

Pumpipumpe creates opportunities for sharing at the scale of a neighbourhood, so as to reduce the purchase of household items but also prompt people to think about product and service design, inspired by the cradle-to-cradle design philosophy. As quoted in Sahakian (2017), the co-founder states that "(s)haring makes sense in the material world as we have it today and would make sense in a world where we have very intelligent products, which go back into recycling". She feels that Pumpipumpe could ultimately influence purchasing decisions: "How we buy, how we select. If you see that there are already two pasta machines in your neighbourhood, you know you don't need to buy one", leading to less material throughput in the economy and less waste.

The initiative has been designed to be simple, accessible to all people, and easy to use. That is why the stickers are composed solely of graphically-designed images (without any text) to facilitate the exchange between neighbours, without difficulties of language or legibility (e.g. easily understandable by children or old people). Participants are free to share their tools, kitchen appliances or toys with their neighbours, however they see fit. This way, Pumpipumpe promotes the free sharing (not renting for money) of personal belongings.

\section{Outcomes and Outputs}

More than 15,000 households in Switzerland, Germany, and Austria have ordered Pumpipumpe stickers, and approximately 9450 addresses are listed on the online platform. However, the association does not keep track of who is using the platform and what sharing activities are actually taking place. In the future, the co-founder envisions a smartphone application for identifying different available items in a given area, but for this, additional funding would be necessary. Beyond virtual connections, she emphasizes the importance of the "real, live network" as she put it:

We live in rather anonymous urban neighbourhoods. We have a beautiful digital network, all over the world [...] With social networks, we are connected with people like us everywhere in the world, but in fact in the real network, in the neighbourhood, it is the opposite. Because it is very 
diversified: there are people with different political points of view, different ages... quite different precisely. But in the same place. So that's exactly the opposite of digital social networks, and [...] I think it's important to connect with people who are different, who do not have the same opinions about everything, who do not have the same habits. And not to be afraid of this discussion, of this interaction with quite different people. ${ }^{2}$

Thus, without large costs, the initiative aims to have a high impact on practices and representations of ownership, consumption, and sharing, and promotes a sufficiency-based lifestyle. There is also coherence between the message (less consuming and more sharing) and the action type (simple to use, appropriable by all, and exchange facilitating). This type of initiative can have an impact on a regional or international scale, as citizens across Europe and elsewhere have already demonstrated their interest in ordering Pumpipumpe stickers. This international diffusion and success is no doubt due to the simplicity of its design and functioning.

\section{ConClusion}

Challenges to achieving the Swiss energy transition and objectives of “2050 Energy Strategy” are particularly related to space heating, mobility, and RE roll out. The specificity of heating in apartment buildings poses a particular challenge: the lack of a resident's control over their own heating system, and possibility to set indoor temperatures, implies that people would have a difficult time reducing indoor temperatures if they wish to do so. Empowering people to be able to adapt their indoor temperatures is a necessary step towards engaging households in the energy transition (Dobigny 2016, 2017). The Swiss energy system, mostly based on local and public utilities, also has an important role to play in the energy transition, particularly due to the trust of population in these local utilities. An interesting development has emerged in relation to renewable energies: to achieve the "turn" towards renewable energy resources, collaborations are underway between utility providers and citizen groups. This is an original development in Switzerland, situated between large-scale RE implementation led by utility companies, and small-scale citizen cooperatives.

\footnotetext{
${ }^{2}$ Interview extract, translated from French. Zurich, Switzerland, December 15, 2017.
} 
The utility companies are also actively engaged in campaigns, initiatives, and $\mathrm{R} \& \mathrm{D}$ to decrease energy usage, often collaborating with community associations or researchers towards this aim. A particularity of the Swiss case is indeed the important role of academics and research teams when it comes to implementing and designing energy initiatives, or re-thinking our relationship to energy and absolute reductions in innovative ways. This is due to an ambitious national research policy that supported research programmes on energy issues in the past decade, with a specific focus on socio-economic approaches to energy, in addition to technical developments. This lesson from Switzerland could inform European policy towards further supporting research-action initiatives drawing from social sciences and the humanities. Another lesson learned from the Swiss SECIs to inform European policy is to account for coherence: much like the Pumpipumpe example given above, the design and functioning of any such initiatives should be coherent. If less energy usage is an aim, more initiatives need to focus on sufficiency, rather than efficiency-and should be designed accordingly.

\section{REFERENCES}

Dobigny, L. (2016). Quand l'énergie change de mains. Socio-anthropologie de l'autonomie énergétique locale au moyen d'énergies renouvelables en Allemagne, Autriche et France (Thèse de Sociologie). Université Paris 1 Panthéon-Sorbonne.

Dobigny, L. (2017). What renewable energy change? The role of technical systems in energy uses and representations. 13th Conference of the European Sociological Association (ESA), Athens, Greece, 29 August-1 September.

Gram-Hanssen, K., \& Georg, S. (2017). Energy performance gaps: Promises, people, practices. Building Research \& Information, 46(1), 1-9.

Jensen, C. L., Goggins, G., Fahy, F., Grealis, E., Vadovics, E., Genus, A., et al. (2018). Towards a practice-theoretical classification of sustainable energy consumption initiatives: Insights from social scientific energy research in 30 European countries. Energy Research o Social Science, 45, 297-306.

Sahakian, M. (2017). Toward a more solidaristic sharing economy: Examples from Switzerland. In M. J. Cohen, H. S. Brown, \& P. J. Vergragt (Eds.), Social change and the coming of post-consumer society: Theoretical advances and policy implications. Oxon and New York: Routledge.

Sahakian, M., \& Bertho, B. (2018). L'électricité au quotidien: le rôle des normes sociales pour la transition énergétique suisse. Genève, Suisse, Fonds national 
suisse (FNS), PNR71. https://www.unige.ch/sciences-societe/socio/files/ 9415/3502/7352/Brochure_PNR71_DEF.pdf.

Sahakian, M., \& Dobigny, L. (2019). From governing behaviour to transformative change: A typology of household energy initiatives in Switzerland. Energy Policy, 129, 1261-1270.

Swiss Confederation. (2016). Energy law, (LEne) of 30th septembre 2016 (entered in force on 1 January 2018), Switzerland. https://www.admin.ch/ opc/fr/classified-compilation/20121295/index.html.

Swiss Federal Office of Energy (SFOE). (2018). Statistique suisse de l'électricité 2017. http://www.bfe.admin.ch/index.html!lang=en.

Vuille F., Favrat, D., \& Erkman, S. (2015). Comprendre la transition énergétique. Presses polytechniques et universitaires romandes.

Open Access This chapter is licensed under the terms of the Creative Commons Attribution 4.0 International License (http://creativecommons.org/licenses/ by $/ 4.0 /$ ), which permits use, sharing, adaptation, distribution and reproduction in any medium or format, as long as you give appropriate credit to the original author(s) and the source, provide a link to the Creative Commons license and indicate if changes were made.

The images or other third party material in this chapter are included in the chapter's Creative Commons license, unless indicated otherwise in a credit line to the material. If material is not included in the chapter's Creative Commons license and your intended use is not permitted by statutory regulation or exceeds the permitted use, you will need to obtain permission directly from the copyright holder.

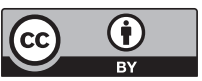

